\title{
EUS-guided thrombin injection for management of gastric fundal varices $\square$
}

\section{(ㄷ)(1) $\odot$}

Authors

John W. Frost, Srisha Hebbar

Institution

Royal Stoke University Hospital - Gastroenterology, Stokeon-Trent, United Kingdom of Great Britain and Northern Ireland

submitted 16.10.2017

accepted after revision 18.12.2017

Bibliography

DOI https://doi.org/10.1055/a-0599-0440 |

Endoscopy International Open 2018; 06: E664-E668

(c) Georg Thieme Verlag KG Stuttgart · New York

ISSN 2364-3722

Corresponding author

John W. Frost, Royal Stoke University Hospital -

Gastroenterology, Newcastle Road, Stoke-on-Trent ST4

6QG, United Kingdom of Great Britain and Northern Ireland john.frost@nhs.net

\section{ABSTRACT}

Background and study aims Cyanoacrylate glue is recommended first-line endoscopic therapy for gastric fundal varices but it is difficult to use and carries a risk of embolization. Thrombin is preferred by many in the UK, but its effectiveness can be difficult to establish at endoscopy and the

rate of re-bleeding is higher. Endoscopic ultrasound (EUS) can help assess variceal blood flow and has the potential to improve both targeting and effectiveness of injection therapy. Whereas there is already some data for its use with glue, little data currently exist in relation to its use with thrombin.

Patients and methods We present a series of patients treated with EUS-guided thrombin injection over the last 4 years. Thrombin was injected under EUS guidance with the intention of obliterating flow within the fundal varices. Outcomes reviewed included whether haemostasis was achieved, the dose of thrombin required for endosonographic variceal obliteration, the incidence of re-bleeding, and procedural related adverse events.

Results Eight patients received EUS-guided thrombin: 3 with active bleeding and 5 as elective prevention. In 2/3 $(66 \%)$ patients with active bleeding haemostasis was achieved after a single dose with complete variceal obliteration. $1 / 3(33 \%)$ had no alteration in blood flow despite $10000 \mathrm{IU}$. None of the elective prevention group had further bleeding and obliteration was observed in $4 / 5$ ( $80 \%)$. A range of 600 to $10000 \mathrm{IU}$ of thrombin was used and there were no adverse procedure-related outcomes.

Conclusions Our results are promising and suggest that EUS-guided thrombin injection may have a role in managing bleeding from gastric fundal varices.

\section{Introduction}

Tissue adhesives such as $\mathrm{N}$-butyl-2-cyanoacrylate glue, are highly effective in managing bleeding from gastric fundal varices (GOV-2/IGV-1) with most series reporting rates of $>90 \%$ for achieving hemostasis [1]. However, there have been a number of reports of systemic embolization of the glue material postinjection, including at least one report of fatal pulmonary embolism [2,3]. It is also difficult to administer, resulting in a damaged endoscope if not prepared properly. With such relatively low number of patients presenting annually with upper gastrointestinal bleeding secondary to gastric fundal varices, it is unsurprising that there is uncertainty amongst endoscopists when it comes to administering glue [4].
Human thrombin can also be used to treat bleeding from gastric fundal varices. It is easy to administer and does not appear to be associated with the same embolic complications as glue, and therefore provides an effective and safe alternative. However, the rates of re-bleeding are often higher, ranging from $7 \%$ to $50 \%$ among series, and given the paucity of data in follow-up and eradication studies, it is often only recommended as bridging therapy to a more definitive treatment such as glue, trans-jugular intrahepatic portosystemic shunt (TIPS), balloon retrograde trans-venous obliteration (BRTO), or transplantation [1,5].

Endoscopic ultrasound (EUS) can assess variceal blood flow and looks to be a useful tool for evaluation, treatment, and estimation of recurrent bleeding potential of gastric fundal vari- 
ces [6-8]. There are a number of case reports and studies describing its successful utilization in management of gastric fundal varices, using glue, coils or a combination of the two [916]. Although there is a case report in the literature on EUSguided thrombin therapy for ectopic varices, to our knowledge nothing currently exists on its use in gastric fundal varices [17]. We present the results of a series of patients treated with this method.

\section{Patients and methods}

\section{Study design}

All patients treated with EUS-guided thrombin injection were included in the report, with the earliest recorded treatment taking place in October 2013 and the latest in January 2017. Patients initially selected for treatment with EUS-guided thrombin injections were on elective varices surveillance lists with persistent gastric fundal varices despite previous attempts at endoscopic eradication. After procedural success with EUSguided thrombin injection was observed in the elective surveillance group, it was then also attempted in patients admitted with active bleeding. Glue is not used in our center for bleeding gastric fundal varices due to the complications outlined above, and therefore, experience with it is limited. As neither TIPS nor BRTO are readily available in our center, human thrombin injection without EUS guidance is often our initial treatment of choice to achieve hemostasis, with radiological intervention being reserved for refractory cases. Informed consent was obtained in all instances.

During the study period, eight patients were treated: three for active variceal hemorrhage and five electively for persistent fundal varices. In the latter group four of five of the patients were also receiving treatment with non-selective beta blockers (NSBBs), with the remaining patient unable to take such medication due to underlying heart block. All procedures were performed by one endosonographer skilled in advanced endoscopic techniques. Outcomes evaluated were as follows:

- Successful achievement of hemostasis, defined as no further episodes of overt bleeding or need for further therapeutic endoscopy/radiological intervention within 3 months;

- Endosonographic evidence of variceal obliteration during thrombin administration;

- Measurement in international units (IU) of the dose of thrombin required to produce variceal obliteration; and

- Incidence of procedure-related adverse events (AEs).

\section{Performing the procedure}

A linear EUS endoscope was placed at the gastroesophageal junction and the fundal varices identified. If a "feeding vessel" could be identified, it was specifically targeted for thrombin therapy, otherwise the largest, most accessible varix/varices were selected and injected under direct ultrasound guidance using a standard 22-gauge EUS needle. Thrombin was either reconstituted with $0.9 \%$ sodium chloride as a $1000 \mathrm{IU} / 5 \mathrm{~mL}$ solution or $2500 \mathrm{IU} / 5 \mathrm{~mL}$ solution dependent on the formulation available to the endoscopy department without use of the gelatine matrix provided. Thrombin was injected either until no further flow was identified on color Doppler (at which point the varix was considered obliterated), or until a maximum of $10000 \mathrm{IU}$ of thrombin was administered. The procedure is demonstrated in our video, which showcases three cases from our study ( $\triangleright$ Video 1 ).

Endoscopic surveillance for patients undergoing thrombin injection electively was booked at 3 or 6 months (depending on the burden of variceal disease and the endoscopist's clinical judgement) and then annually thereafter depending on procedural success.

Endoscopic surveillance for patients successfully treated in the active variceal hemorrhage was booked at 4 weeks initially, with further follow-up at 3 and 12 months if endosonographic obliteration was achieved.

\section{Results}

All patients included in the study had established cirrhotic liver disease with three patients having co-existing portal vein thrombosis. For ease of reference, we present the demographic data in > Table 1. Please note that other than being classified as "active variceal hemorrhage" and "elective prevention," the patients are presented in no particular order and do not necessarily correlate to the cases demonstrated in the video.

\section{Active variceal hemorrhage}

Among those receiving EUS-guided thrombin therapy for active variceal hemorrhage, two of three patients (67\%) had an excellent response to therapy with successful hemostasis and complete endosonographic variceal obliteration with $4250 \mathrm{IU}$ and $7500 \mathrm{IU}$, respectively. In addition, there has been no recorded incidence of re-bleeding with a mean follow-up time of 100 days.

In one of three patients (33\%), therapy was unsuccessful and the patient went on to have further bleeding. During the procedure $10000 \mathrm{IU}$ of thrombin was administered with no significant alteration in variceal blood flow, therefore, the procedure

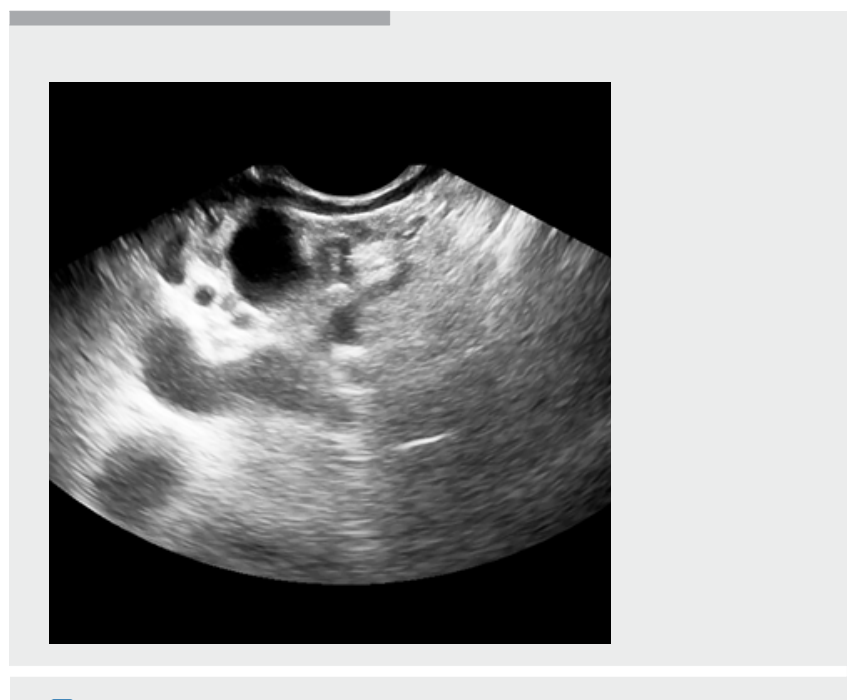

Video 1 EUS-guided thrombin injection of gastric varices. 
- Table 1 Participant demographic data.

\begin{tabular}{|c|c|c|c|c|c|c|c|c|c|c|}
\hline Patient & Age & Sex & Diagnosis & PVT & $\begin{array}{l}\text { Child Pugh } \\
\text { Score }\end{array}$ & MELD & $\begin{array}{l}\text { Sarin clas- } \\
\text { sification }\end{array}$ & $\begin{array}{l}\text { Thrombin } \\
\text { dose }\end{array}$ & $\begin{array}{l}\text { Obliteration } \\
\text { successful? }\end{array}$ & $\begin{array}{l}\text { Did OV require } \\
\text { treatment? }\end{array}$ \\
\hline \multicolumn{11}{|c|}{ Active hemorrhage } \\
\hline 1 & 40 & M & ALD $^{1}$ & No & $11(\mathrm{C})$ & 22 & GOV-2 & $10000 \mathrm{IU}$ & No & $\begin{array}{l}\text { No (grade 1; } \\
\text { no red sign) }\end{array}$ \\
\hline 2 & 64 & M & NAFLD & Yes & $6(A)$ & 10 & GOV-2 & $7500 \mathrm{IU}$ & Yes & EBL \\
\hline 3 & 68 & M & $\mathrm{ALD}^{1}$ & No & $8(B)$ & 12 & IGV-1 & $4250 I U$ & Yes & - \\
\hline \multicolumn{11}{|c|}{ Elective prevention } \\
\hline 4 & 67 & M & NAFLD & No & $5(A)$ & 7 & IGV-1 & $1000 \mathrm{IU}$ & Yes & - \\
\hline 5 & 70 & M & $A L D+N A F L D$ & Yes & 7 (B) & 10 & IGV-1 & $600 I U$ & Yes & - \\
\hline 6 & 58 & M & $\mathrm{ALD}+\mathrm{HCV}$ & No & $6(A)$ & 9 & IGV-1 & $5000 \mathrm{IU}$ & $\mathrm{No}^{2}$ & - \\
\hline 7 & 72 & $\mathrm{~F}$ & NAFLD & No & $6(A)$ & 11 & GOV-2 & $5000 \mathrm{IU}$ & Yes & $\begin{array}{l}\text { No (grade 1; } \\
\text { no red sign) }\end{array}$ \\
\hline 8 & 55 & M & $\begin{array}{l}\text { Cryptogenic } \\
\text { cirrhosis and } \\
\text { myelofibrosis } \\
(J A K 2+)\end{array}$ & Yes & 7 (B) & 8 & GOV-2 & $1000 \mathrm{IU}$ & Yes & EBL \\
\hline \multicolumn{11}{|c|}{$\begin{array}{l}\text { PVT, portal vein thrombosis; MELD, model for end-stage liver disease; OV, esophageal varices; ALD, alcoholic liver disease; NAFLD, non-alcoholic fatty liver disease; } \\
\text { HCV, Hepatitis C virus; EBL, endoscopic band ligation. } \\
1 \text { Patients with ongoing high levels of alcohol consumption. }\end{array}$} \\
\hline
\end{tabular}

was abandoned and the decision was made to refer for urgent TIPS (Case 3 in $>$ Video 1). Unfortunately, the patient subsequently discharged himself against advice and died from a further variceal hemorrhage at a later date. That was the only death recorded in the study and we believe that given the circumstances, it was essentially unavoidable and unrelated to use of thrombin.

There were no direct procedure-related AEs observed.

\section{Elective prevention}

Complete endosonographic variceal obliteration was noted in five of five patients (100\%) undergoing EUS-guided thrombin therapy for prevention of future bleeding. The dose of thrombin used ranged from 600IU to 5000IU (mean 2520IU) and none of the patients have had further bleeding with a mean follow-up time of 723 days. In four of five patients (80\%), gastric fundal varices have remained eradicated on surveillance endoscopy and no further treatment has been required. In one of five patients (20\%) surveillance endoscopy revealed persistent variceal disease despite previously documented procedural success. Due to a booking error, that patient had his initial surveillance endoscopy at 8 months as opposed to the 3 months intended by the endoscopist. There were no direct procedurerelated complications observed.

\section{Discussion}

Variceal hemorrhage only accounts for around $10 \%$ of admissions for acute upper gastrointestinal bleeding, with up to one-third of those being secondary to gastric varices $[4,18]$. Al- though bleeding from gastric varices tends to occur less frequently, it is often more severe and associated with a higher rate of mortality than bleeding from esophageal varices [19]. Although the reasons for this are multi-factorial, a significant contributing factor has to be the difficulty in administering endoscopic treatment.

EUS-guided thrombin injection appears to have advantages over standard administration as it allows for direct visualization and targeting of the variceal network. In our case series using human thrombin, only one of eight patients (13\%) had further bleeding post-treatment which is potentially very promising given its ease of administering the injections. Human thrombin works through direct clot formation within the vessel, thereby obstructing blood flow and resulting in hemostasis in $70 \%$ to $100 \%$ of cases of gastric variceal bleeding [1]. The reasons behind previously reported high re-bleeding rates therefore are unclear when compared with the results from our study; however, we would postulate that submucosal (as opposed to intravariceal) injection and insufficient thrombin load may constitute a significant proportion. We were able to demonstrate that larger doses of thrombin are required when treating active bleeding to achieve endosonographic variceal obliteration, while earlier studies used much lower doses of thrombin on average (1500-2000 IU), potentially suggesting an inadequate reduction in variceal blood flow when thrombin is injected without EUS guidance $[1,20]$. In support of this theory, human thrombin is routinely used to successfully control bleeding from pseudo-aneurysm formation after cardiac catheterization, which is normally performed under direct visualization with 
ultrasound guidance and has a cumulative success rate of $97 \%$ [21].

In our "elective prevention" group, one of our patients seemed to have restoration of blood flow on surveillance endoscopy despite previously observed endosonographic obliteration. This is interesting and might presumably be due to the body's natural fibrinolytic pathways breaking down the clot over time. In this case, the surveillance endoscopy was unintentionally performed at 8 months and raises questions as to what the optimal time for endoscopic surveillance should be. This patient had a further EUS-guided procedure with thrombin administration, but on this occasion, there was no alteration in variceal flow demonstrated. Given the disappointing response to treatment, further attempts at endoscopic eradication were abandoned with plans to refer for TIPSS in the event of future bleeding. This decision was ultimately made by the patient's hepatologist, and it is important to emphasize that should the expertise be available, treatment with glue or other EUS-guided treatments (such as coil insertion) could be considered prior to interventional radiology.

During the study period the optimal time for repeat endoscopy was largely unknown and therefore the surveillance protocol was designed somewhat pragmatically dependent on the endoscopist's clinical judgement. Currently it is our local policy to perform follow up at 1, 3 and 12 months post-treatment provided endosonographic obliteration is observed, however, more research needs to be performed before we can make specific recommendations on endoscopic surveillance.

There are clear limitations to our study. First, the numbers are small and therefore the study is insufficiently powered to draw any firm conclusions regarding safety or efficacy of the proposed treatment. The data have not been collected prospectively, and therefore the surveillance endpoints among patients differ according to when they were first treated. It would also have been useful to have included a comparison group of patients, either receiving "blind" thrombin as per our department's standard operating practice or perhaps more helpfully against cyanoacrylate glue, given that it remains the recommended first-line modality for endoscopic treatment of gastric fundal varices. In cases in which a "feeding" vessel had been identified, it would have been helpful to specifically document this as it may well account for some of the variations seen in the amounts of thrombin required for obliteration and degree of procedural success [22]. Finally, in patients receiving EUS-guided thrombin therapy electively, it is unclear whether absence of further bleeding was the result of endosonographic variceal obliteration or NSBB use, particularly as one of the patients had persistent varices at surveillance but did not re-bleed, and that would need to be factored in to any studies going forward.

\section{Conclusions}

The results of our study are promising and we would certainly advocate a role for the use of EUS in management of gastric fundal varices. As a general measure it allows for direct visualization and targeting of injection therapy, provides a good estimate of when treatment has been successful, and facilitates early planning for further procedures, should endosonographic variceal obliteration be unsuccessful.

Use of EUS-guided thrombin injection was effective in the patients in our case series, resulting in a lower risk of re-bleeding than that previously seen with standard thrombin administration and cyanoacrylate glue. Given the difficulties and adverse effects associated with tissue adhesives, we hope that thrombin will provide a viable alternative to use of cyanoacrylate glue as first-line endoscopic therapy in the future, but more work needs to be done in this area in order to draw any firm conclusions. We would suggest a prospective evaluation of a larger cohort going forward.

\section{Competing interests}

None

\section{References}

[1] Garcia-Pagán JC, Barrufet M, Cardenas A et al. Management of gastric varices. Clin Gastroenterol Hepatol 2014; 12: 919-928

[2] Tan YM, Goh KL, Kamarulzaman A et al. Multiple systemic embolisms with septicemia after gastric variceal obliteration with cyanoacrylate. Gastrointest Endosc 2002; 55: 276-278

[3] Audibert M, Schoeffler M, Wallet F et al. Acute fatal pulmonary embolism during cyanoacrylate injection in gastric varices. Gastroentérol Clin Biol 2008; 32: 926 - 930

[4] Sarin SK, Lahoti D, Saxena SP et al. Prevalence, classification and natural history of gastric varices: A long-term follow-up study in 568 portal hypertension patients. Hepatology 1992; 16: 1343-1349

[5] Smith MR, Tidswell R, Tripathi D. Outcomes of endoscopic human thrombin injection in the management of gastric varices. Eur J Gastroenterol Hepatol 2014; 26: 846-852

[6] El-Saadany M, Jalil S, Irisawa A et al. EUS for portal hypertension: a comprehensive and critical appraisal of clinical and experimental indications. Endoscopy 2008; 40: 690 -696

[7] Sgouros SN, Vasiliadis KV, Pereira SP. Systematic review: endoscopic and imaging-based techniques in the assessment of portal haemodynamics and the risk of variceal bleeding. Alimentary Pharmacol Therapeutics 2009; 30: 965-976

[8] Bissonnette J, Paquin S, Sahai A et al. Usefulness of endoscopic ultrasonography in hepatology. Can J Gastroenterol 2011; 25: 621-625

[9] Romero-Castro R, Pellicer-Bautista F, Giovannini M et al. Endoscopic ultrasound (EUS)-guided coil embolization therapy in gastric varices. Endoscopy 2010; 42: E35-E36

[10] Binmoeller KF, Weilert F, Shah JN et al. EUS guided trans oesophageal treatment of gastric fundal varices with combined coiling and cyanoacrylate glue injection (with videos). Gastrointest Endosc 2011; 74: $1019-1025$

[11] Bhat YM, Weilert F, Fredrick RT et al. EUS-guided treatment of gastric fundal varices with combined injection of coils and cyanoacrylate glue: a large U.S. experience over 6 years (with video). Gastrointest Endosc 2016; 83: $1164-1172$

[12] Lee YT, Chan FK, Ng EK et al. EUS-guided injection of cyanoacrylate for bleeding gastric varices. Gastrointest Endosc 2000; 52: 168-174

[13] Romero-Castro R, Pellicer-Bautista F], Jimenez-Saenz M et al. EUSguided injection of cyanoacrylate in perforating feeding veins in gastric varices: results in 5 cases. Gastrointest Endosc 2007; 66: 402 407 
[14] Romero-Castro R, Ellrichmann M, Ortiz-Moyano C et al. EUS-guided coil versus cyanoacrylate therapy for the treatment of gastric varices: a multicenter study (with videos). Gastrointest Endosc 2013; 78: $711-721$

[15] Gubler C, Bauerfeind P. Safe and successful endoscopic initial treatment and long-term eradication of gastric varices by endoscopic ultrasound-guided Histoacryl (N-butyl-2-cyanoacrylate) injection. Scand J Gastroenterol 2014; 49: 1136-1142

[16] Fujii-Lau LL, Law R, Wong Kee Song LM et al. Endoscopic ultrasound (EUS)-guided coil injection therapy of esophagogastric and ectopic varices. Surg Endosc 2016; 30: 1396 - 1404

[17] Krystallis C, McAvoy NC, Wilson J et al. EUS-assisted thrombin injection for ectopic bleeding varices - a case report and review of the literature. QJM 2012; 105: 355-358
[18] Jairath V, Rehal S, Logan R et al. Acute variceal haemorrhage in the United Kingdom: patient characteristics, management and outcomes in a nationwide audit. Dig Liver Dis 2014; 46: 419-426

[19] Wani ZA, Bhatt RA, Bhadoria AS et al. Gastric varices: Classification, endoscopic and ultrasonographic management. J Res Med Sci 2015; 20: $1200-1207$

[20] Yang WL, Tripathi D, Therapondos G et al. Endoscopic use of human thrombin in bleeding gastric varices. Am J Gastroenterol 2002; 97: $1381-1385$

[21] Webber GW, Jang J, Gustavon J et al. Contemporary management of postcatheterization pseudoaneurysms. Circulation 2007; 115: 2666 2674

[22] Arakawa M, Masuzaki T, Okuda K. Pathomorphology of esophageal and gastric varices. Semin Liver Dis 2002; 22: $73-82$ 